\title{
Pigmented Villonodular Synovitis for Combined Therapy
}

\author{
Alexander P Rozina, g, Gabriel Nierenberg ${ }^{\mathrm{b}}$, Euvgeni Vlodavsky ${ }^{\mathrm{c}}$, Kohava Toledano ${ }^{\mathrm{a}}$, \\ Natanel Meushar ${ }^{d}$, Kamal Yassine, Rahamim Ben-Yosef ${ }^{\mathrm{f}}$
}

\begin{abstract}
Pigmented villonodular synovitis (PVNS), inflammatory proliferative disease resulting from synovial cells, has progressive course similar neoplastic local expansion. We followed up a case with effective combined therapy for diffuse PVNS despite incomplete response to its components and reviewed therapies based on MedLine for PVNS. Due to US data residue synovitis after open radical synovectomy, we made decision about external beam radiotherapy. Photon radiation with linear accelerator energy of $6 \mathrm{MV}$ was applied for two fields: anterior and posterior. The total dose was 20 Gy, delivered in 2 Gy a day, five times a week. Due to postoperative pain and the rest of synovial tissue on US study, pharmacologic therapy with salazopyrine and celecoxib was added. For several weeks, the knee pain became episodic and further disappeared. Six months later, the patient feels healthy and continues to take salazopyrine permanently and celecoxib as needed. We conclude high rate response analyzing literature data and our case to combined therapy: arthroscopic or open surgery followed by RT along with complimentary pharmacotherapy.
\end{abstract}

Keywords: Pigmented villonodular synovitis; Open synovectomy; External beam radiotherapy; Anti-inflammatory medications

Manuscript accepted for publication December 11, 2013

${ }^{a} B$. Shine Department of Rheumatology, Rambam Health Care Capus and Technion, Haifa, Israel

${ }^{\mathrm{b}}$ Department of Orthopedic Surgery, Rambam Health Care Capus and Technion, Haifa, Israel

${ }^{\mathrm{c}}$ Department of Pathology, Rambam Health Care Capus and Technion, Haifa, Israel

${ }^{\mathrm{d}}$ Orthopedic Oncology Unit, Rambam Health Care Capus and Technion, Haifa, Israel

e Department of Gastroenterology and Clalit Health Services, Rambam Health Care Capus and Technion, Haifa, Israel

f Department of Radiotherapy, Rambam Health Care Capus and Technion, Haifa, Israel

${ }^{g}$ Corresponding author: Alexander Rozin, B. Shine Department of Rheumatology, Rambam Health Care Campus and Technion, PO Box 9602, Haifa 31096, Israel. Email: a_rozin@rambam.health.gov.il

doi: http://dx.doi.org/10.14740/jmc1656e

\section{Introduction}

Described as inflammatory tumor of tendon [1], pigmented villonodular synovitis (PVNS) got name due to macroscopically appearance: pigmented color, villi and nodules [2]. This is inflammatory proliferative disease resulting from synovial cells [3]. PVNS has progressive course similar neoplastic local expansion [4]. In the advanced stages, synovial inflammation (pannus) can invade cartilage, bone, capsule with joint destruction [5]. Recurrent synovial hemorrhages are transformed by phagocytes to extra- and intracellular hemosiderin deposits seen on MRI study as "blooming" artefacts (MRI gradient-echo) and on biopsy specimens [6]. Nodular structure of histiocytic infiltrates with multinucleated giant cells, foam cells and dense fibrosis are common histologic findings [7]. Despite very rare polyarticular disease (children), monoarticular involvement is predominant, when knee, hip and ankle are usually affected with pain, swelling and disability. Several forms of PVNS were described: diffuse intra-articular, localized intra-articular, giant cell tumor of tendon sheath and pigmented villonodular bursitis. Overexpression of M-CSF plays a pathogenic role in PVNS. The annual incidence estimated is $1-2$ /million persons/year [8]. Mean age of the disease onset is $33 \pm 13$ years with no gender predilection. Histologically PVNS may mimic rhabdomyosarcoma, synovial carcinoma or epithelioid sarcoma. Malignant transformation of PVNS is extraordinary [9]. Most cases of PVNS have translocations involving CSF1 located at $1 \mathrm{p} 13$ [10]. We followed up a case with effective combined therapy for diffuse PVNS despite incomplete response to its components.

\section{Case Report}

A 41-year-old white woman, teacher, was suffering from recurrent right knee hemorrhagic inflammatory effusions for 2 years without history of trauma, data for blood dyscrasia, crystallopathy or coagulopathy. Intra-articular corticosteroid injections were helpful for several days only. Three diagnostic arthroscopy events showed massive diffuse synovial 


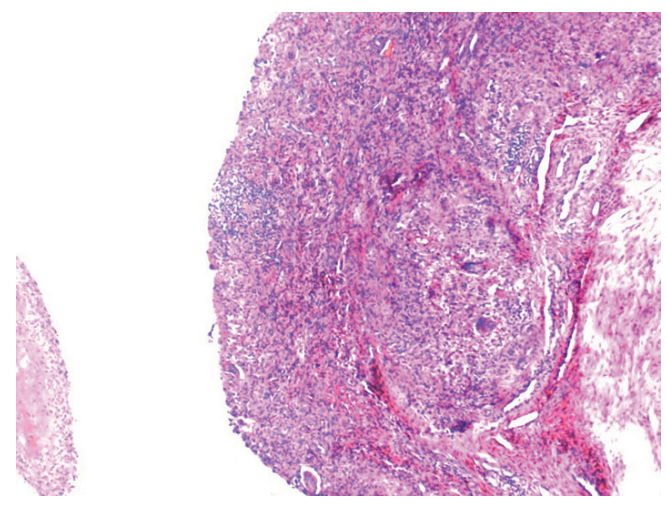

Figure 1. Pigmented villonodular synovitis. Synovia with dense cellular infiltration by mononuclear and giant cells and hemosiderin (brownish areas) deposition. Hematoxylin\&eosin $\times 50$. Hemosiderin often forms after bleeding (hemorrhage). When blood leaves a ruptured blood vessel, the red blood cells die and the hemoglobin of the cell is released into the extracellular space. Macrophages engulf (phagocytose) the hemoglobin to degrade it, producing hemosiderin.

hypertrophy without bacterial growth of usual or fast acid pathogens. MRI and synovial biopsy disclosed high T-2 signals/inflammatory infiltrate with multinucleated giant cells and hemosiderin deposits (Fig. 1). Diagnosis of diffuse form of pigmented villonodular synovitis was made and the patient was presented for open radical synovectomy, which was performed without complications. Nevertheless complete excision of inflammatory tissue the operated knee movements stayed limited (Fig. 2, left) and US of the knee showed the synovitis residue, partially invading the quadriceps ligament (Fig. 3, left). Due to US data and high rate of PVNS relapse $(8-56 \%)$ for 5 years [11], we made decision about external beam radiotherapy [12]. Photon beam irradiation (6 MV) through opposed anterior and posterior fields was given. The total dose was $20 \mathrm{~Gy}$, delivered in $2 \mathrm{~Gy}$ a day, five times a week. The knee movement improved after radiotherapy (Fig. 2 , right) and synovitis reduced significantly by physical examination and US (Fig. 3, right). Due to postoperative pain and the rest of synovial tissue on US study, pharmacologic therapy with salazopyrine $2 \mathrm{~g}$ /day and celecoxib $400 \mathrm{mg}$ /day was added. For several weeks, the knee pain became episodic and further disappeared. Six months later, the patient feels healthy and continues to take salazopyrine permanently and celecoxib as needed.

\section{Discussion}

Recent studies showed that anti-inflammatory therapy with anti-TNF biologics (infliximab systemic and etanercept intra-articular) and anticancer imatinib (tyrosine-kinase inhibitor of signaling cascade) may be helpful in management of PVNS [10, 13, 14]. Large amounts of TNF-alpha were found in PVNS similarly to rheumatoid arthritis (RA). But synovitis of PVNS is considered as a secondary reaction to a neoplastic disorder. The pathologic mechanism for growth of hypertrophic villi in PVNS is different from synovial growth in RA. Synovial hyperplasia in PVNS might be due to upregulation of synoviocyte proliferation as represented by activation of telomerase, which is evident in the majority of tumor cell lines [15]. That is why the treatment such as with TNF-alpha blockade did not reduce synovial tumor mass as measured by MRI but alleviated and stabilized synovial inflammation and joint effusion $[13,14]$. However, treatment with imatinib showed MRI decrease in size of lesions in 50\% of patients. Stable disease was observed in 33\% patients. But patients showed progression after discontinuation of imatinib [10]. From this point of view, it is not surprising that the first step in treatment of PVNS is considered to be radical synovectomy. We believe that open access may be more radical. It is similar principle of maximal removing of tumor tissue in treatment of other neoplasia for the best survival. But arthroscopic access was reported to be also successful [16]. Despite synovectomy group of RA patients deteriorated more slowly than medication group, after 2-3 years, the group had the same pattern of deterioration [17]. PVNS treated by synovectomy had also recurrence rate as high as

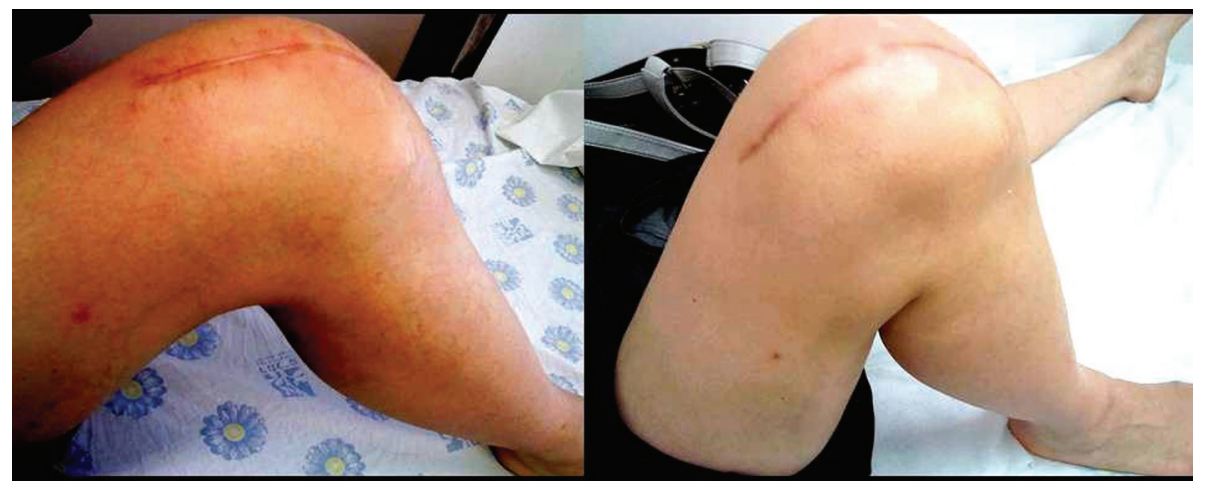

Figure 2. Pigmented villonodular synovitis. Maximal knee flexion after radical synovectomy (left) and combined (surgery + RT) therapy (right: returned to normal). 


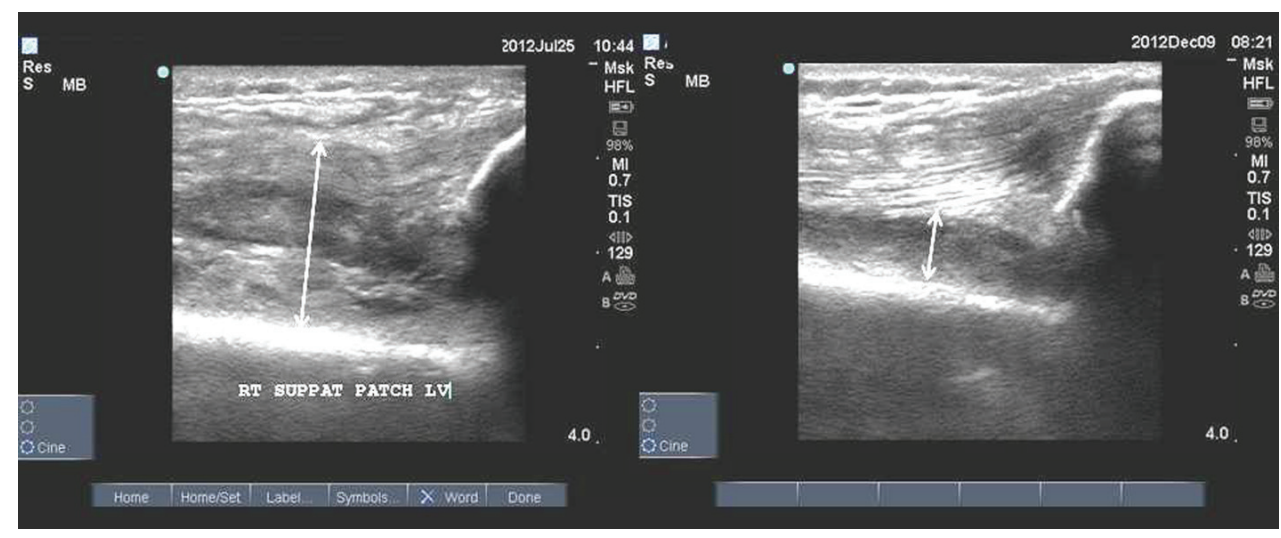

Figure 3. Pigmented villonodular synovitis. US Iongitudinal suprapatellar view study. The synovitis residue after radical synovectomy is seen on the left figure. The rest of synovitis decreased after radiotherapy (right figure).

$45 \%$ [18-20]. However, the treatment of choice for PVNS is a complete synovectomy performed arthroscopically or through an open arthrotomy $[21,22]$. The long-term success of surgery for PVNS, as with others tumor lesions, depends on the ability to excise the disease completely [22]. The use of adjuvant radiation therapy (RT) following primary resection for high risk lesions may improve local disease control $[18,23,24]$.

RT may be used as the primary treatment for diffuse intra-articular PVNS, but it is best used to augment surgery following incomplete resection of disease. RT may be instituted either by external beam or through intra-articular injections (yttrium-90, rhenium-186) [11, 25, 26]. Initial and highly satisfactory experience with the injection of radioactive yttrium 90 to treat PVNS of the ankle joint eroded with time [27]. Full thickness skin necrosis in two patients, development of draining sinus in third associated with chronic pain and severe chronic pain in other four patients urged recommendation to discontinue its use [27].

Several recent publications showed favorable effect of external beam RT as a postoperative treatment $[11,12,18$, 28-31]. The GCG-BD group conducted a pattern-of-care study to analyze the RT for PVNS [12]. Thirty patients received postsurgical RT because of primarily incomplete resection, 11 patients as an adjunct after complete resections of recurrences or unclear resection status. The total doses ranged from 30 to $50 \mathrm{~Gy}$ (median $36 \mathrm{~Gy}$ ), in 2 Gy a day. Local control was achieved in $95.1 \%$, and $82.9 \%$ had no or only slight functional impairment.

In another report, eight patients with diffuse PVNS of the knee were treated with subtotal arthroscopic synovectomy followed by local adjuvant RT. Two weeks after surgery, RT was applied with a 15-MV linear accelerated photon beam. The total dose ranged from 10 to $39.60 \mathrm{~Gy}$, with mean of 20 Gy divided on average into 10 fractions every 2 days in 20 days. The dose of radiation was determined based on the protocol of the RT service and used in accordance with the expected biologic effect. Only one patient was classified as recurrence after brief period of relief. Follow-up for a mean 8.6 years showed no arthritis progression, postoperative complications or RT late effect in seven patients. Two developed quadricipital muscle atrophy and one synovial effusion [28].

In another work, seven patients with diffuse PVNS underwent radical surgery and RT (30-50 Gy). No evidence of recurrence was found; one patient had persistent restriction of joint movement after surgery [11].

One more recent trial describes review of 23 patients after postoperative RT for PVNS [29]. Nineteen patients had primary disease and 4 had recurrent disease with an average of 2.5 prior surgeries. After synovectomy (17 arthroscopic surgeries; 6 open), all 23 patients received 4-6 MV external beam radiotherapy with a median dose of 20 (12-34) Gy in 10 fractions. Of these four patients, three received salvage synovectomy and regained local control. Twenty-two patients reported excellent or good joint function, and one who refused salvage synovectomy had poor joint function. None of the patient experienced significant radiation toxicity or secondary malignancy in a median $\mathrm{F} / \mathrm{U}$ of 9 years. Low-dose (20 Gy) RT appears to be as effective as moderate-dose RT (35 Gy) [29].

Recent Egypt study demonstrated 12 patients with diffuse knee PVNS, which postoperatively (open anterior and posterior debulking) were treated with external beam RT (26-30 Gy) 5 fractions per week (2 Gy/fraction) 6-8 weeks after surgery with mean follow-up of 27 months. No evidence of local recurrence or joint destruction was noted on clinical and MRI studies. No complications of surgery or RT were recorded. The functional outcome of the involved joint in all patients was good according to Enneking's criteria (postoperative score 85\%) [30].

In another trial, 14 patients had undergone combined knee synovectomy and RT. The RT was applied in two fields with 1.2-1.5 Gy a fraction in 5 fractions per week to a to- 
tal dose of 16-20 Gy. The combined therapy was used due to difficulties of complete removal of the affected synovial tissue even with total capsulectomy. During the follow-up period (6 months to 6 years), there were no recurrences of PVNS and occupational rehabilitation was attained in $87.5 \%$ of the patients [31].

Twenty-two patients with diffuse PVNS of the knee had been treated with combined arthroscopic synovectomy and postoperative external beam RT (total dose 26 Gy). Recurrence was found in three patients. Articular stiffness and residual edema were found in three patients, two of whom had persistent pain [18].

However, results of surgery and adjuvant therapy are not uniformly positive. Radiosynovectomy alone or in combination with surgery, compared with use of surgery alone, did not improve patient outcome in another publication [32]. Nevertheless such single data, recurrent diffuse intra-articular PVNS is often treated with combined therapy. We compared a rate of relapse for diffuse PVNS after surgery with data of relapse after combined therapy (surgery + RT) from above mentioned reports. This resulted in $45 \%$ for surgical (arthroscopic or open) versus $6.9 \%$ for combined (surgery + RT) therapy of PVNS relapse for 2-5 years.

The limitations of most studies are its retrospective design, which may have introduced selection bias, and the small number of patients. Due to the low incidence of PVNS, it is difficult to perform large-scale prospective controlled studies.

Our case showed the residue of synovitis after radical open synovectomy by US control. The PVNS residual synovitis protruded quadriceps ligament (Fig. 3, left). After RT, the focus of inflammation reduced leaving quadriceps ligament to be spare (Fig. 3, right). We recommend US as valuable investigation for diagnosis of PVNS remnants after arthroscopic or open surgery.

Anti-inflammatory pharmacotherapy may be helpful in management of postoperative and post-radiation period in patients with persistent inflammation and pain.

\section{Conflict of Interests}

None.

\section{References}

1. Chassaignac M. Cancer de la gaine des tendons. Gaz Hop Civ Milit. 1852;47:185-186.

2. Jaffe HL, Lichtensein L, Sutro CJ. Pigmented villonodular synovitis, bursitis, and tenosynovitis. Arch Pathol. 1941;31:731-765.

3. O'Connell JX, Fanburg JC, Rosenberg AE. Giant cell tumor of tendon sheath and pigmented villonodular sy- novitis: immunophenotype suggests a synovial cell origin. Hum Pathol. 1995;26(7):771-775.

4. Choong PF, Willen H, Nilbert M, Mertens F, Mandahl N, Carlen B, Rydholm A. Pigmented villonodular synovitis. Monoclonality and metastasis--a case for neoplastic origin? Acta Orthop Scand. 1995;66(1):64-68.

5. Chiari C, Pirich C, Brannath W, et al. What affects the recurrence and clinical outcome of pigmented villonodular synovitis? Clin Ortop Rel Res. 2006;450:172-178.

6. Singh R, Grewal DS, Chakravarti RN. Experimental production of pigmented villonodular synovitis in the knee and ankle joints of rhesus monkeys. J Pathol. 1969;98(2):137-142.

7. Granowitz SP, D'Antonio J, Mankin HL. The pathogenesis and long-term end results of pigmented villonodular synovitis. Clin Orthop Rel Res. 1976;114:335-351.

8. Myers BW, Masi AT. Pigmented villonodular synovitis and tenosynovitis: a clinical epidemiologic study of 166 cases and literature review. Medicine (Baltimore). 1980;59(3):223-238.

9. Yoon HJ, Cho YA, Lee JI, Hong SP, Hong SD. Malignant pigmented villonodular synovitis of the temporomandibular joint with lung metastasis: a case report and review of the literature. Oral Surg Oral Med Oral Pathol Oral Radiol Endod. 2011;111(5):e30-36.

10. Ravi V, Wang W, Araujo DM, Ludwig JA, Luke RJ, Lewis VO, et al. Imatinib in the treatment of tenosynovial giant-cell tumor and pigmented villonodular synovitis. J Clin Oncol. 2010;(suppl;10011)28:15s.

11. Berger B, Ganswindt U, Bamberg M, Hehr T. External beam radiotherapy as postoperative treatment of diffuse pigmented villonodular synovitis. Int J Radiat Oncol Biol Phys. 2007;67(4):1130-1134.

12. Heyd R, Micke O, Berger B, Eich HT, Ackerman H, Seegenschmiedt MH. Radiation therapy for treatment of pigmented villonodular synovitis: results of national patterns of case study. Int J Radiation Oncology Biol Phys. 2010;78:199-204.

13. Kroot EJ, Kraan MC, Smeets TJ, Maas M, Tak PP, Wouters JM. Tumour necrosis factor alpha blockade in treatment resistant pigmented villonodular synovitis. Ann Rheum Dis. 2005;64(3):497-499.

14. Fiocco U, Sfriso P, Oliviero F, Sovran F, Scagliori E, Pagnin E, Vezzu M, et al. [Intra-articular treatment with the TNF-alpha antagonist, etanercept, in severe diffuse pigmented villonodular synovitis of the knee]. Reumatismo. 2006;58(4):268-274.

15. Yudoh K, Matsuno H, Nezuka T, Kimura T. Different mechanisms of synovial hyperplasia in rheumatoid arthritis and pigmented villonodular synovitis: the role of telomerase activity in synovial proliferation. Arthritis Rheum. 1999;42(4):669-677.

16. Asil M, Erlap L, Altinel L, Cetik O. Localized pigmented villlonodular synovitis of the knee. J Arthrosc Relat 
Surgery. 2001;17:1-6.

17. Meijers KA, Valkenburg HA, Cats A. A synovectomy trial and the history of early knee synovitis in rheumatoid arthritis. A multicentre study. Rheumatol Int. 1983;3(4):161-166.

18. Blanco CE, Leon HO, Guthrie TB. Combined partial arthroscopic synovectomy and radiation therapy for diffuse pigmented villonodular synovitis of the knee. Arthroscopy. 2001;17(5):527-531.

19. Hogan CJ, Diduch DR. Patellar instability as a result of localized pigmented villonodular synovitis. Am J Knee Surg. 2001;14(4):259-263.

20. Kat S, Kutz R, Elbracht T, Weseloh G, Kuwert T. Radiosynovectomy in pigmented villonodular synovitis. Nuklearmedizin. 2000;39(7):209-213.

21. Durr HR, Stabler A, Maier M, Refior HJ. Pigmented villonodular synovitis. Review of 20 cases. J Rheumatol. 2001;28(7):1620-1630.

22. Murphey MD, Rhee JH, Lewis RB, Fanburg-Smith JC, Flemming DJ, Walker EA. Pigmented villonodular synovitis: radiologic-pathologic correlation. Radiographics. 2008;28(5):1493-1518.

23. Marberry K, Lowry K, Griffiths H, Kenter K. Radiologic case study. Pigmented villonodular synovitis. Orthopedics. 2001;24(7):647, 710-642.

24. Kotwal PP, Gupta V, Malhotra R. Giant-cell tumour of the tendon sheath. Is radiotherapy indicated to prevent recurrence after surgery? J Bone Joint Surg Br. 2000;82(4):571-573.

25. Kollender Y, Bender B, Nirkin A, et al. Intra-articular yttrium-90 injection as an adjuvant following resection of diffusepigmented villlonodular synovitis. J Bone Joint
Surg Br. 2005;87(suppl 3):387.

26. O'Sullivan B, Cummings B, Catton C, Bell R, Davis A, Fornasier V, Goldberg R. Outcome following radiation treatment for high-risk pigmented villonodular synovitis. Int J Radiat Oncol Biol Phys. 1995;32(3):777-786.

27. Bickels J, Isaakov J, Kollender Y, Meller I. Unacceptable complications following intra-articular injection of yttrium 90 in the ankle joint for diffuse pigmented villonodular synovitis. J Bone Joint Surg Am. 2008;90(2):326328.

28. de Carvalho LH, Jr., Soares LF, Goncalves MB, Temponi EF, de Melo Silva O, Jr. Long-term success in the treatment of diffuse pigmented villonodular synovitis of the knee with subtotal synovectomy and radiotherapy. Arthroscopy. 2012;28(9):1271-1274.

29. Park G, Kim YS, Kim JH, Lee SW, Song SY, Choi EK, Yi SY, et al. Low-dose external beam radiotherapy as a postoperative treatment for patients with diffuse pigmented villonodular synovitis of the knee: 4 recurrences in 23 patients followed for mean 9 years. Acta Orthop. 2012;83(3):256-260.

30. Nassar WA, Bassiony AA, Elghazaly HA. Treatment of diffuse pigmented villonodular synovitis of the knee with combined surgical and radiosynovectomy. HSS J. 2009;5(1):19-23.

31. Ustinova VF, Podliashuk EL, Rodionova SS. [Combined treatment of the diffuse form of pigmented villonodular synovitis]. Med Radiol (Mosk). 1986;31(3):27-31.

32. de Visser E, Veth RP, Pruszczynski M, Wobbes T, Van de Putte LB. Diffuse and localized pigmented villonodular synovitis: evaluation of treatment of 38 patients. Arch Orthop Trauma Surg. 1999;119(7-8):401-404. 